\title{
РОЛЬ НЕФИНАНСОВОЙ ОТЧЕТНОСТИ В ПОВЫШЕНИИ ИМИДЖА КОМПАНИИ
}

\section{(c) 2020 Басова Мария Михайловна}

кандидат экономических наук, доцент Департамента учета, анализа и аудита Финансовый университет при Правительстве Российской Федерации, Россия, Москва E-mail:MMBasova@fa.ru

В статье показана роль категории «нефинансовая отчетность организации» для формирования позитивного имиджа в сознании заинтересованных сторон. На примере нефинансовой отчетности «На высоте возможностей» Группы «Аэрофлот» показан механизм оценки имиджа организации различными группами стейкхолдеров с указанием соответствия элементов имиджа компании разделам отчетности.

Ключевые слова: Имидж организации; нефинансовая отчетность организации; стейкхолдеры; бренд; индекс потребительской лояльности; структура имиджа компании; элементы имиджа компании.

В широком смысле слова, имидж - это некий образ, формируемый в сознании целевой аудитории. Первоочередной задачей владельца любого бизнеса является развитие позитивного имиджа организации. Имидж любой компании оказывает психологическое, информационное и эмоциональное воздействие на заинтересованные группы, тем самым манипулируя их выбором. Он может быть положительным и отрицательным. Сложившийся положительный имидж компании позволяет формировать устойчиво позитивное представление о ней всех заинтересованных сторон и будет достаточно долго работать на развитие бизнеса.

Как известно, все усилия по формированию положительного имиджа организации направлены на привлечение потенциальных клиентов; улучшение условий работы и развитие самого персонала, транслирующего позитивную информацию в массы и дающего в целом представление о компании, как о надежном работодателе; получение в партнеры надежную компанию на основе поддержания своей репутации, как финансово стабильной компании; установку рабочих отношений со СМИ (влияние которых на сознание людей также нельзя недооценивать) с целью получения положительно окрашенной информации о компании; а также так или иначе влияющих на деятельность организации органов власти (местная власть, органы правопорядка, налоговые службы, органы санитарного и экологического надзора и др.). Положительная репутация фирмы с последними будет способ- ствовать содействию с их стороны и в значительной степени отсутствию различных противодействий.

Реализуя политику социальной ответственности, компании постоянно открывают новые механизмы формирования своего имиджа. Если постоянно не заниматься работой над имиджем организации, то ее всерьез не будут воспринимать спонсоры и партнеры, упадет узнаваемость на рынке, не станут рекомендовать друзьям и знакомым и предпочтение будет отдаваться конкурентам, что в конечном итоге неизбежно приведет к снижению доходности компании. Но для того, чтобы этого не произошло, информацию о своих «благих делах» нужно своевременно и умело донести до интересующих компанию заинтересованных сторон.

На наш взгляд, решению задачи по формированию положительного имиджа организации может послужить нефинансовая отчетность. Целью нефинансовой отчетности, в которую включается самая существенная информация о компании, является предоставление данных, позволяющих всем заинтересованным сторонам оценивать способность компании создавать ценность на протяжении времени. По сути, нефинансовую отчетность можно назвать неким PR-документом, который, при грамотно и достоверно представленной в нем информации, способен закрепить компанию на лидирующих позициях [2]. Стоит заметить, что на сегодняшний день, такую отчетность в России составляют в основном крупные и серьезные организации, 
следовательно, и сама ее публикация уже говорит о представительности компании. Поскольку имидж складывается из таких нематериальных активов, как надежность, доверие, прозрачность отношения с клиентами, качество, а также материальных активов в виде инвестиций в человеческий капитал и окружающую среду, то отказ от составления нефинансовой отчетности может негативным образом повлиять на стоимость всей компании.

Нефинансовая отчетность позволяет улучшать имидж, узнаваемость бренда компании для всех групп стейкхолдеров [5]. Ключевым преимуществом такой отчётности при создании имиджа компании, является её доступность не только менеджменту, но и всем заинтересованным сторонам, включая клиентов, партнеров, инвесторов, СМИ, органы власти. Так, например, доступность информации не только о финансово-экономической, но и об экологической и социальной деятельности компании позволит инвесторам провести тщательный анализ рисков и увеличит вероятность инвестирования финансовых и нефинансовых средств в деятельность такой компании.

Нефинансовая отчетность «На высоте возможностей» Группы «Аэрофлот» за 2018 год [6], крупнейшей в России авиакомпании, направлена на поддержание своего высокого имиджа, тратящей на это ежегодно около 800 миллионов рублей. Компания, входящая в топ-20 авиаперевозчиков мира по пассажиропотоку, является одним из крупнейших авиаперевозчиков Европы, занимает лидирующие позиции на российском рынке авиаперевозок, как на внутренних, так и на международных магистральных маршрутах. В отчетности отмечается, что рыночная доля Группы «Аэрофлот» на российском рынке в 2018 году составила 40,7\%. Аэрофлот обладает рейтингом «четыре звезды» от британской кон- салтинговой компании Skytrax и «пять звезд» от американской авиационной ассоциации APEX, семь раз был удостоен премии Skytrax World Airline Awards в категории «Лучшая авиакомпания Восточной Европы».

Анализ нефинансовой отчетности компании показал, что она ориентирована на узнаваемость бренда для всех групп стейкхолдеров, определяя тем самым структуру имиджа компании.

Прежде всего это имидж для клиентов, включающий их мнение о компании, о заявленной ею миссии и стратегии развития. С целью оперативного выявления и устранения проблемных зон продукта и сервиса на всех этапах взаимодействия с клиентом, как отмечается в нефинансовой отчетности компании, проводится мониторинг уровня выполнения стандартов обслуживания пассажиров авиакомпании «Аэрофлот» на основе методологии «Скрытый пассажир». По итогам реализации четырех волн проекта (с декабря 2017 по ноябрь 2018 года) средний показатель по Компании составил 89,5\%, положительная динамика показателей отмечена по всем зонам сервиса.

Динамика индекса потребительской лояльности авиакомпании «Аэрофлот» представлена на рисунке 1.

В отчетности также отмечается, что повышение качества обслуживания на земле и на борту - один из ключевых приоритетов Группы «Аэрофлот». Авиакомпании Группы постоянно ищут возможности усовершенствования сервиса, проводят аудиты качества продукта на разных уровнях, в том числе на международном. В 2018 году более 97\%1 клиентов, обратившихся в контактный центр Аэрофлота, поставили высокую оценку качества обслуживания («4» и «5» по 5-балльной шкале). Это на $12 \%$ выше нормы, установленной требованиями отраслевого стандарта COPC Customer Experience Standard 2016. В

\section{Динамика индекса потребительской лояльности (NPS) авиакомпании «Аэрофлот» (\%)}

\begin{tabular}{l|lll}
\hline 2018 & & 72 \\
\hline 2017 & & 72 \\
\hline 2013 & $\vdots$ & 58 \\
\hline 2010 & $\vdots$ & 44 \\
\hline
\end{tabular}


2018 году Аэрофлот был повторно назван самым узнаваемым авиационным брендом в мире в рейтинге Brand Finance. CX World Awards 2018 в номинации «Лучший клиентский опыт в В2С секторе» Одна из высших наград European Contact Centre \& Customer Service Awards (ECCCSA) В 2018 году за высокое качество обслуживания клиентов контактцентр Аэрофлота был отмечен международными премиями В 2018 году обслуживание пассажиров по программе Sky Priority введено по всей сети маршрутов авиакомпании «Россия», а также в аэропортах вылета дальневосточного перевозчика «Аврора».

Как следует из отчетности, каждая авиакомпания Группы гарантирует своим клиентам безупречную безопасность и высококачественный сервис на всех этапах авиапутешествия и стре-

\section{Финансовые показатели}

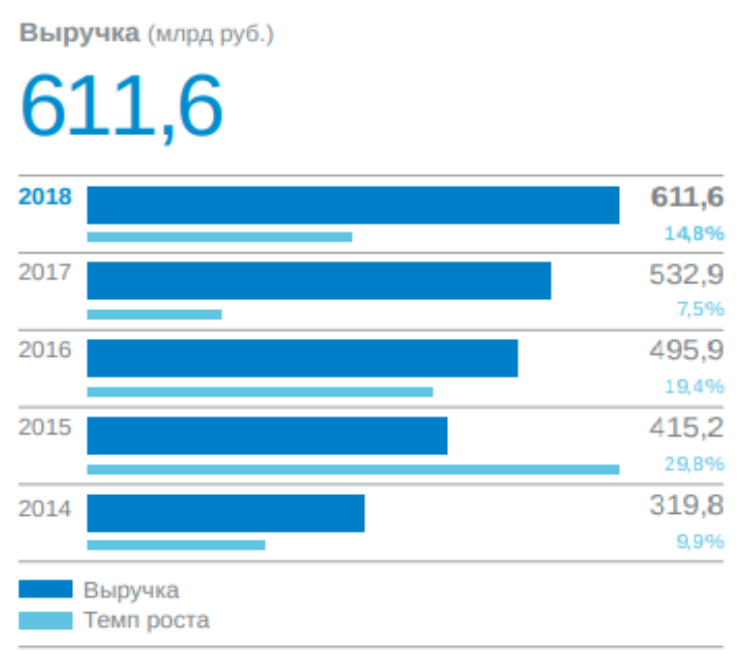

EBITDA (млрд руб.) и рентабельность по EBITDA (\%)
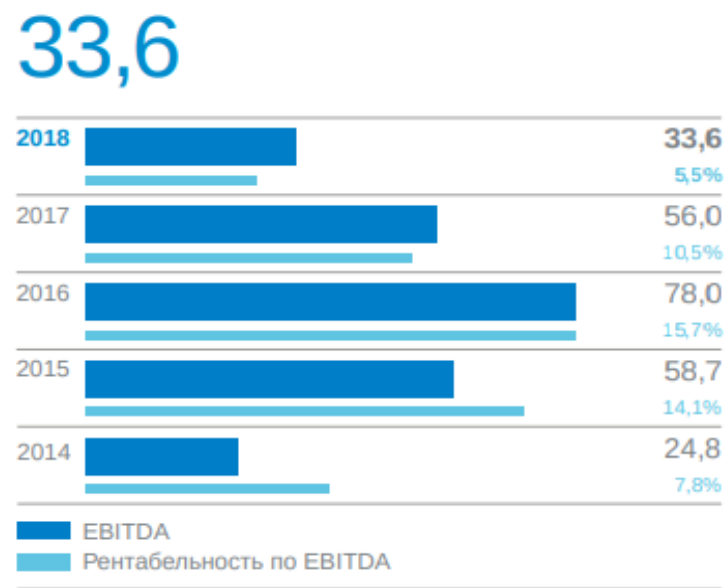

мится превосходить ожидания своих клиентов.

«Бизнес имидж» в нефинансовой отчетности Группы «Аэрофлот» представлен информацией, характеризующей ее высокую деловую репутацию и финансовую устойчивость, которая в первую очередь интересна ее партнерам. Так, высокие финансовые показатели (рисунок 2) повлияли на увеличение числа партнеров программы «Аэрофлот Бонус». В 2018 году к программе «Аэрофлот Бонус» присоединилось 66 новых партнеров. Общее количество партнеров по состоянию на конец года составило 190, включая 20 авиакомпаний. В течение года авиакомпания продолжила открывать новые возможности по использованию миль для приобретения товаров и услуг неавиационных партнеров. Среди партнеров «Аэрофлот Бонус» банки, отели,

EBITDAR (млрд руб.) и рентабельность по EBITDAR (\%)
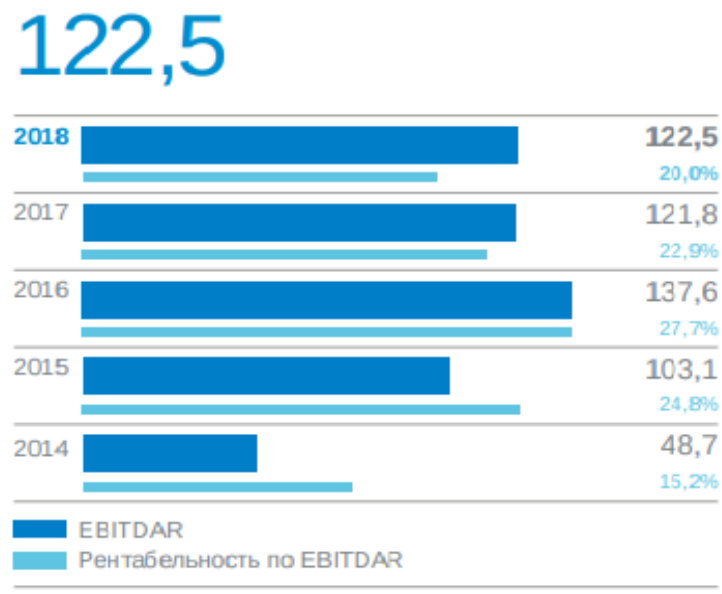

Чистая прибылы(убыток) (мпрд руб.)
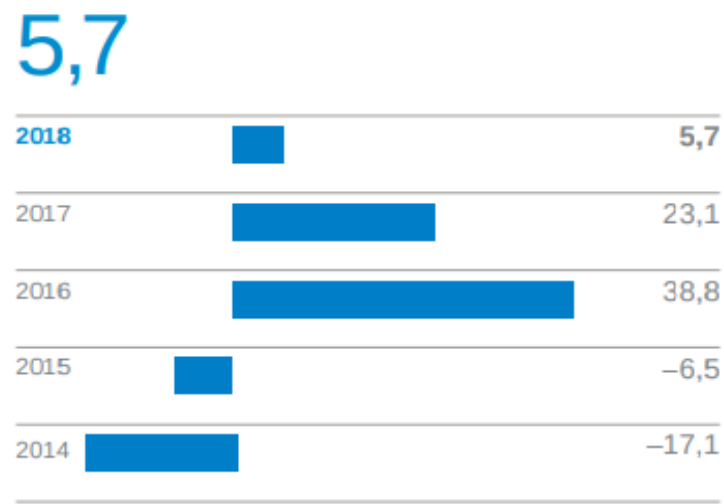

Puc. 2. Финансовые показатели деятельности авиакомпании «Аэрофлот» 
компании по аренде автомобилей, интернетмагазины, ритейлеры, рестораны.

Значительное место в нефинансовой отчетности авиакомпании «Аэрофлот» уделяется проблемам повышения ее социально-экологического имиджа. В отчетности авиакомпании можно увидеть социальные цели и роль организации в жизни общества через информирование о социальных аспектах своей деятельности.

По данным отчетности можно утверждать, что компания заботится и об экологии путем непрерывного повышения энергетической и экологической эффективности, используя современный молодой парк воздушных судов и самые передовые технологии, обеспечивая тем самым соответствие своей деятельности российскому законодательству в области охраны окружающей среды.

Компания в полной мере осознает свою ответственность перед обществом и посредством нефинансовой отчетности показывает свое активное участие в социально значимых и благотворительных проектах, эффективном сотрудничестве с местными и национальными некоммерческими организациями.

В нефинансовой отчетности Группы «Аэрофлот» представлена информация связанная со значимостью авиаперевозок и доказывающая свой высокий имидж в глазах государственных структур.

Внутренний имидж организации - отражает мнение коллектива о самой организации и наличии благоприятного социально-экономического климата в коллективе и влияет на представление работников компании о них самих. Анализ нефинансовой отчетности Группы «Аэрофлот» показал, что организацию по имиджу можно отнести к успешной, она является ведущим работодателем на рынке авиаперевозок, привлекательной в отношении оплаты труда, желанию персонала к повышению квалификации и уверенности его в завтрашнем дне. Привлечение, удержание и профессиональное развитие специалистов является одним из приоритетных направлений деятельности компании. Повышение эффективности работы и производительности труда через создание уникальной команды высокопрофессиональных и вовлеченных сотрудников стратегическая цель кадровой политики. Компания выделяет приоритетным направлением формирование корпоративной культуры как конкурентного преимущества. ПАО «Аэро- флот» успешно использует в своей работе Кодекс корпоративной этики.

В нефинансовой отчетности детально представлена информация, свидетельствующая о том, что ПАО «Аэрофлот» и дочерние компании реализуя ряд программ социального характера, которые способствуют обеспечению социальной защищенности персонала, среди них: негосударственное пенсионное обеспечение, санаторнокурортное лечение, организация спортивных мероприятий, предоставление служебного жилья ключевым специалистам, дополнительные социальные льготы для летного состава.

Так, например, как отмечается в годовом отчете компании за 2018 год, «в рамках программы санаторно-курортного лечения работники и члены их семей направляются в санаторнокурортные учреждения различных регионов России и за рубеж (по медицинским показаниям). В 2018 году в санаторно-курортных учреждениях прошли лечение 3,8 тыс. человек, в том числе 797детей сотрудников совместно с родителями прошли лечение по программе «Здоровый ребенок». Для летного состава была организована специальная реабилитационновосстановительная программа в Чехии, лечение по которой прошли 420 пилотов и бортпроводников. Всего в программу 2018 года было включено 13 санаториев. В 2018 году в программу санаторно-курортного лечения и оздоровительного отдыха работников и членов их семей были включены программы добровольного медицинского страхования и предупреждения травматизма и профессиональных заболеваний» [7].

Соответствие элементов имиджа компании разделам нефинансовой отчетности Группы «Аэрофлот» представлено в таблице 1.

Поскольку репутация любой компании складывается из таких нематериальных активов, как доверие, надежность, качество, прозрачность, отношения с клиентами, а также материальных активов в виде инвестиций в человеческий капитал и окружающую среду, то отказ от нефинансовой отчетности может оказать негативное влияние, как на стоимость компании, так и на ее имидж. Доступность информации не только о финансовой, но и об экономической и социальной деятельности компании позволяет заинтересованным лицам проводить тщательный анализ интересующей их информации и делать соответствующие выводы о ее имидже. 
Таблица 1. Соответствие элементов имиджа компании разделам нефинансовой отчетности Группы «Аэрофлот»

\begin{tabular}{|c|c|c|}
\hline $\begin{array}{c}\text { Элементы имиджа } \\
\text { компании }\end{array}$ & Характеристика & $\begin{array}{c}\text { Разделы нефинансовой отчетности } \\
\text { Группы «Аэрофлот», где представлены } \\
\text { элементы }\end{array}$ \\
\hline $\begin{array}{l}\text { 1. Историко- } \\
\text { концептуальный блок }\end{array}$ & $\begin{array}{l}\text { Отражает миссию организации, ее цели, } \\
\text { задачи }\end{array}$ & $\begin{array}{l}\text { Группа «Аэрофлот» сегодня } \\
\text { Авиакомпании Группы } \\
\text { Основные события } 2018 \text { года } \\
\text { Признание пассажиров и награды } \\
\text { История Компании } \\
\text { Положение на рынке } \\
\text { Стратегия развития } \\
\text { Повышение качества услуг и укрепление } \\
\text { бренда }\end{array}$ \\
\hline 2. Финансовый блок & $\begin{array}{l}\text { Отражает финансово-экономические } \\
\text { показатели деятельности организации }\end{array}$ & $\begin{array}{l}\text { Динамика ключевых операционных и } \\
\text { финансовых показателей } \\
\text { Инвестиционная привлекательность } \\
\text { Бизнес-модель } \\
\text { Операционные результаты Финансовые } \\
\text { результаты }\end{array}$ \\
\hline $\begin{array}{l}\text { 3. Социально- } \\
\text { экологический блок }\end{array}$ & $\begin{array}{l}\text { Отражает общественную роль органи- } \\
\text { зации как внутри компании, так и за ее } \\
\text { пределами, включая заботу компании о } \\
\text { своих работниках, проведение благотво- } \\
\text { рительных акций, реализация социаль- } \\
\text { ных программ, экологическую политику }\end{array}$ & $\begin{array}{l}\text { Кадровая политика } \\
\text { Содействие развитию регионов и благо- } \\
\text { творительность } \\
\text { Спонсорство } \\
\text { Экология и охрана окружающей среды }\end{array}$ \\
\hline
\end{tabular}

\section{Библиографический список}

1. Басова М. М. Краснослободизев А. А. Междисциплинарный дискурс категории бренд. Вопросы современной науки и практики. Университет им. В.И. Вернадского. 2009. № 12. С. 30.

2. Басова М. М. Содержательный анализ нефинансовой отчетности российских компаний в области устойчивого развития//Вестник СамГУПС.-2016. -№ 4 (34). -С. 52-56.

3. Дорожкина Т.В., Крутиков В.К., Аракелян С.А., Федорова О.В. Корпоративная социальная ответственность. Учебно-методическое пособие. Калуга: Изд-во «Эйдос», 2015.-С. 13-15.

4. Когденко В.Г., Мельник М.В. Интегрированная отчетность: вопросы формирования и анализа // Международный бухгалтерский учет. 2014. № 10 (304). С. 2-15.

5. ФатееваТ.Н., Лесина Т.В. Нефинансовая отчетность как инструмент формирования положительного имиджа организации// Интернет-журнал «НАУКОВЕДЕНИЕ» Том 7, No4(2015) http://naukovedenie.ru/ PDF/57EVN415.pdf (доступ свободный). Загл. с экрана. Яз. рус., англ.DOI: 10.15862/57EVN415

6. Официальный сайт Российского союза промышленников и предпринимателей [Электронный ресурс] URL: http://www.rspp.ru (дата обращения: 10.09.2019).

7. Годовой отчет «На высоте возможностей» Группы «Аэрофлот» за 2018 год [Электронный pecypc] - URL: https://ir.aeroflot.ru/fileadmin/user_upload/files/rus/reports/annual_reports/aeroflot_ar18_rus.pdf (дата обращения: 20.09.2019). 